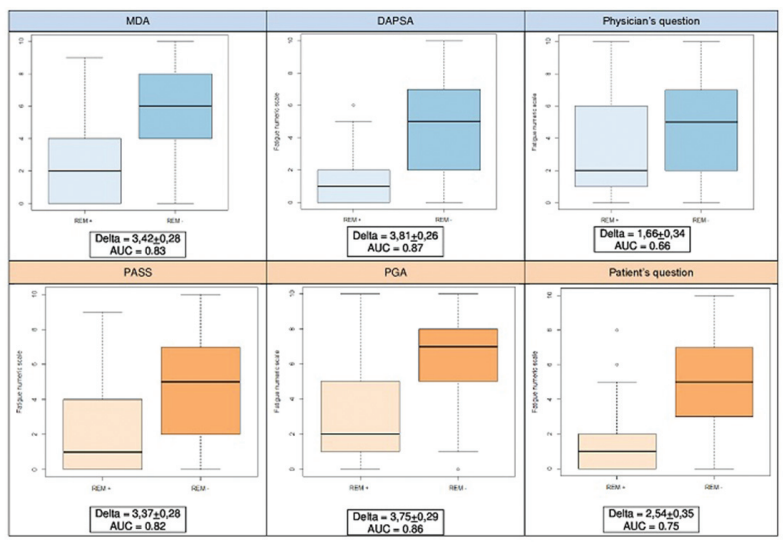

Conclusions: Fatigue levels were relatively high in these PsA patients whose disease was often well-controlled. Fatigue was lower in patients in remission, according to all definitions of remission; the remission definition with best knowngroups validity for fatigue was DAPSA remission. Moreover both composite measures perform better than the physicians opinion of remission. These elements may be important in a context of shared decision-making.

Acknowledgements: This study was funded by Pfizer.

Disclosure of Interest: None declared

DOI: 10.1136/annrheumdis-2018-eular.3106

\section{SAT0319 DESCRIPTION OF MUSCULOSKELETAL SYMPTOMS IN A COHORT OF PATIENTS WITH PSORIASIS}

C. Magee $^{1}$, F. Farkas ${ }^{1}$, N. Ikumi ${ }^{1}$, A. Szentpetery ${ }^{1}$, P. Gallagher ${ }^{1}$, B. Kirby ${ }^{2}$, O. Fitzgerald $1 .{ }^{1}$ Rheumatology; ${ }^{2}$ Dermatology, St. Vincent's University Hospital, Dublin, Ireland

Background: The BIOmarkers of COMorbidities (BIOCOM) in Psoriasis (Pso) study is a longitudinal study which aims to identify clinical, genetic or protein biomarker features associated with the development of co-morbidities, notably Psoriatic Arthritis (PsA) in patients with Pso. Pso usually precedes the development of PsA with an average interval of 10 years. Thus, Pso patients are an ideal group in which to study the early events in the evolution to PsA.

Objectives: Herein we describe the baseline clinical features in this BIOCOM cohort. Based on these features, we categorise patients into groupings which may be helpful during long-term follow-up.

Methods: Patients are being recruited from the dermatology clinics at St. Vincent's University Hospital, Dublin. Inclusion criteria included a diagnosis of Pso with disease duration of less than 10 years and an age of 18 years or older. Patients with another serious active medical illness, a previous diagnosis of inflammatory arthritis or those who were receiving systemic immunosuppressant therapy for Pso were excluded

Following recruitment, patients were assessed for musculoskeletal (MSK) signs or symptoms: questionnaire detailing history of any MSK complaints including inflammatory back pain, full physical examination including evidence of tender or swollen joints and entheseal tenderness (using the Leeds Enthesitis Index) and routine blood testing including inflammatory markers.

If patients had any MSK findings they underwent routine radiographs, MRI scanning or ultrasound scanning as indicated. Patients were then categorised using all information available as follows: Pso only; PsO+: MSK signs or symptoms but insufficient for diagnosis of PsA; PsA (CASPAR): Diagnosis of PsA meeting CASPAR criteria; Other Rheumatic Disease.

Abstract SAT0319 - Table 1. Breakdown of Features of Inflammatory Articular Disease

\begin{tabular}{lc}
\hline MSK Finding(s) & No. of Patients (total 96) \\
\hline Tender or Swollen Joint(s) (T/S J) only & 41 \\
Enthesitis (E) only & 12 \\
Inflammatory Back Pain (IBP) only & 10 \\
T/S J and E & 20 \\
T/S J and IBP & 3 \\
E and IBP & 2 \\
T/S J, E and IBP & 8 \\
\hline
\end{tabular}

Of these 96 patients, 79 patients had some additional imaging studies.

Results: To date 190 patients with Psoriasis have been recruited. Of those, 9 were excluded due to a diagnosis of Pso $>10$ years previously. One was excluded due to a previous diagnosis of JIA
Of the remaining 180 patients: 106 were male (58.9\%). Mean age was 41.5 \pm 14.8 years. Average duration of $P$ so: $6.1 \pm 2.9$ years.

On examination: $126(70 \%)$ had psoriatic nail disease (pitting, ridges or onycholysis).

84 patients had no musculoskeletal signs or symptoms. The remaining 96 patients had at least one musculoskeletal finding as outlined in table 1 below.

Abstract SAT0319 - Table 2. shows how patients were subsequently categorised based on their history, clinical examination, laboratory blood results and imaging.

Breakdown of Diagnoses of BIOCOM patients at baseline (180)

\begin{tabular}{lc}
\hline Pso only & 84 \\
\hline Pso+ & 64 \\
PsA (CASPAR) & 7 \\
Other Rheumatic Disease & 25 \\
\hline
\end{tabular}

Conclusions: Analysis of patients recruited to date for the BIOCOM-Pso study shows that at baseline at least one third of patients with Pso had non-specific MSK signs and symptoms. Previous studies suggest these patients may be more likely to subsequently develop PsA. By following this cohort prospectively, we hope to better characterise which features are predictive of the development of PsA in patients with Pso.

Disclosure of Interest: None declared

DOI: 10.1136/annrheumdis-2018-eular.5578

\section{SAT0320 RELIABILITY ANALYSIS OF THE MADRID SONOGRAPHIC ENTHESIS INDEX (MASEI) AND DIFFERENT DOPPLER SUBGROUPS IN PSORIATIC ARTHRITIS}

C. Macía Villa ${ }^{1}$, S. Falcao ${ }^{2}$, E. De Miguel ${ }^{3} .{ }^{1}$ Rheumatology, Hospital Universitario Severo Ochoa, Madrid, Spain; ${ }^{2}$ Rheumatology, CEDOC, NOVA Medical School, UNL. CHLO, EPE., Lisboa, Portugal; ${ }^{3}$ Rheumatology, Hospital Universitario La Paz, Madrid, Spain

Background: Enthesitis is the cornerstone of spondyloarthritis, and ultrasound (US) indexes have emerged in the last years being the Madrid Sonographic Enthesis Index (MASEI) one of the more widely used.

Objectives: To evaluate the reliability of MASEI and different enthesis power doppler (PD) definitions in Psoriastic Arthritis (PsA).

Methods: 27 consecutive non selected PsA patients were included. An US expert rheumatologist performed the MASEI examination using a MyLab 70 XVG machine, Esaote, Genova, Italy, with a greyscale (GS) $13 \mathrm{MHz}$ probe and 7.1 $\mathrm{MHz}$ power Doppler (PD) frequency, PRF $750 \mathrm{~Hz}$ and 60 Gain. US images and 3-5 s videos were obtained in transversal and longitudinal views for further reliability analysis. The inter-reader reliability analysis was performed by three readers and true US result was the consensus of at least two of them. In addition to the PD item of MASEI (defined as signal in bone profile or intratendon or bursa on the enthesis area), three other PD definitions were evaluated as present or absent: PD OMERACT (PD signal at enthesis $\leq 2 \mathrm{~mm}$ to the bone profile), PD bursa (PD signal inside bursa) and PD tendon (PD signal in the enthesis tendon $>2 \mathrm{~mm}$ from the bone profile). Intraclass correlation coefficient (ICC) estimations and $95 \%$ con fident intervals were calculated for the reliability analysis of MASEI and PD subgroups based on a mean-rating $(k=3)$, absolute-agreement, two-way mixed effect model. Cohen's Kappa test was used for analysis of MASEI's items reliability. SPSS statistical package version 20 (SPSS Inc, Chicago, IL) was used.

Results: Inter-reader reliability of MASEI and PD subgroups is shown in table 1 PD bursa showed the lowest reliability. MASEI, PD MASEI, PD OMERACT and $P D$ tendon showed good to excellent reliability, being PD tendon the best one table 2 shows reliability data of each MASEI lesion in each enthesis included in the index. Best agreement percentages and kappa values were found in erosions and PD with mainly good to excellent data, while the worst ones were found in calcifications with poor to moderate values.

Abstract SAT0320 - Table 1. Inter-reader reliability of MASEI and PD subgroups. Scores expressed as mean $\pm S D$ for each reader.

\begin{tabular}{lccccc}
\hline & Reader $\mathbf{1}$ & Reader 2 & Reader 3 & ICC & 95\% Cl \\
\hline MASEI & 28,52 & 31,89 & 31,30 & 0922 & $0,852-$ \\
& $\pm 13,43$ & $\pm 13,99$ & $\pm 14,14$ & & 0962 \\
PD MASEI & $6,44 \pm 5,80$ & $6,89 \pm 6,43$ & $6,78 \pm 5,43$ & 0921 & $0,851-$ \\
& & & & & 0962 \\
PD & $1,25 \pm 1,32$ & $1,41 \pm 1,65$ & $1,11 \pm 1,39$ & 0895 & $0,802-$ \\
OMERACT & & & & & 0949 \\
PD BURSA & $0,30 \pm 0,67$ & $0,18 \pm 0,56$ & $0,11 \pm 0,42$ & 0776 & $0,576-$ \\
& & & & & 0891 \\
PD TENDON & $1,96 \pm 1,74$ & $2,15 \pm 2,09$ & $2,22 \pm 1,82$ & 0934 & $0,876-$ \\
& & & & &
\end{tabular}


Abstract SAT0320 - Table 2. Inter-reader reliability and agreement analysis of MASEI components. All items were categorised as yes/no. N/A not applicable since one of the lectors offers the same result for all cases, so kappa can't be calculated in this item due to sparse differences between lectors. N/B enthesis without bursa.

\begin{tabular}{|c|c|c|c|c|c|c|c|}
\hline & & $\begin{array}{c}\text { Abnormal } \\
\text { tendon structure }\end{array}$ & $\begin{array}{c}\text { Thickened } \\
\text { tendon }\end{array}$ & Erosion & $\begin{array}{c}\text { Enthesis } \\
\text { calcification }\end{array}$ & Enthesis PD & Bursitis \\
\hline $\begin{array}{l}\text { Triceps tendon } \\
\text { enthesis }\end{array}$ & $\begin{array}{l}\text { Mean kappo } \\
\text { Mean agreement }\end{array}$ & 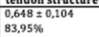 & $\begin{array}{l}0.68 \text { andon } \\
86,42 \%, 103\end{array}$ & $\begin{array}{l}0,808=0,160 \\
95,53 \%\end{array}$ & 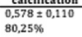 & $\begin{array}{l}0.0628=0,193 \\
95,06 \% 6\end{array}$ & $\mathrm{~N} / \mathrm{B}$ \\
\hline $\begin{array}{l}\text { Quadriceps tendon } \\
\text { enthesis }\end{array}$ & \begin{tabular}{|l} 
Mean kappe \\
Mean agreement
\end{tabular} & $\begin{array}{l}0.529=0,103 \\
76,55 \%\end{array}$ & $\begin{array}{l}0,580=0,100 \\
79,01 \%,\end{array}$ & $\begin{array}{l}1,000=0,000 \\
100 \%\end{array}$ & $\begin{array}{l}0.487=0,115 \\
78,88 \%\end{array}$ & $\begin{array}{l}0.610=0,110 \\
82,71 \%\end{array}$ & $\mathrm{~N} / \mathrm{B}$ \\
\hline $\begin{array}{l}\text { Proximal patellar } \\
\text { IIgament enthesis }\end{array}$ & $\begin{array}{l}\text { Mean kappo } \\
\text { Mean agreement }\end{array}$ & $\begin{array}{l}0.507 \geq 0.116 \\
77,77 \%\end{array}$ & $\begin{array}{l}0.071 \pm 0.100 \\
83,95 \%\end{array}$ & \begin{tabular}{|l}
$0.475=0,181$ \\
$88.89 \%$
\end{tabular} & $\begin{array}{l}0.230 \geq 0,094 \\
58,03 \%\end{array}$ & $\begin{array}{l}0.732 \pm 0.137 \\
93,83 \%\end{array}$ & $\mathrm{~N} / \mathrm{B}$ \\
\hline $\begin{array}{l}\text { Distal patellar } \\
\text { Higament enthesis }\end{array}$ & \begin{tabular}{|l|} 
Mean kappe \\
Mean agreement
\end{tabular} & $\begin{array}{l}0.258=0.153 \\
80,25 \%\end{array}$ & $\begin{array}{l}0,493 \pm 0,125 \\
81,48 \%\end{array}$ & $\begin{array}{l}1,000=0.000 \\
100 \%\end{array}$ & $\begin{array}{l}0.438 \geq 0,122 \\
77,77 \%\end{array}$ & $\begin{array}{l}0.88550 .069 \\
95,06 \% 5\end{array}$ & 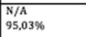 \\
\hline $\begin{array}{l}\text { Achilles tendon } \\
\text { enthesis }\end{array}$ & $\begin{array}{l}\text { Mean kappe } \\
\text { Mean agreement }\end{array}$ & $\begin{array}{l}0.474 \pm 0,106 \\
72,84 \%\end{array}$ & $\begin{array}{l}0.784=0,094 \\
91,36 \%\end{array}$ & $\begin{array}{l}0,953=0,046 \\
98,77 \%\end{array}$ & $\begin{array}{l}0,407=0,146 \\
81,48 \%\end{array}$ & $\begin{array}{l}0 ., 12200,088 \\
92,59 \%\end{array}$ & $\begin{array}{l}0,782=0,113 \\
93,83 \%\end{array}$ \\
\hline $\begin{array}{l}\text { Plantarapo } \\
\text { enthesis }\end{array}$ & \begin{tabular}{|l} 
Mean $\mathrm{kappa}$ \\
Mean agreement
\end{tabular} & $\begin{array}{l}0,427=0,119 \\
72,84 \%\end{array}$ & $\begin{array}{l}0,75220,088 \\
87,04 \%\end{array}$ & $\begin{array}{l}{\left[\begin{array}{l}1,000 \\
100 \%\end{array}\right.} \\
10,000\end{array}$ & $\begin{array}{l}0.171100,058 \\
45,68 \%\end{array}$ & $\begin{array}{l}\mathrm{N} / \mathrm{A} \\
98,77 \%\end{array}$ & $\mathrm{~N} / \mathrm{B}$ \\
\hline
\end{tabular}

Conclusions: MASEI has demonstrated to be a reliable tool in PsA. Erosions and PD showed the best reliability values. Evaluating different definitions of enthesis $P D$, signal in the tendon was the most reliable one, followed with minimal differences by PD MASEI and PD OMERACT, and in last place PD bursa.

Disclosure of Interest: None declared

DOI: 10.1136/annrheumdis-2018-eular.4274

\section{SAT0321 IXEKIZUMAB TREATMENT SIGNIFICANTLY IMPROVES ENTHESITIS AND DACTYLITIS IN PATIENTS WITH ACTIVE PSORIATIC ARTHRITIS: RESULTS FROM THE SPIRIT TRIALS}

D.D. Gladman ${ }^{1}$, A.-M. Orbai ${ }^{2}$, G. Gallo ${ }^{3}$, J. Birt ${ }^{3}$, S. Rathmann ${ }^{3}$, H. Marzo-Ortega ${ }^{4}$. ${ }^{1}$ University of Toronto, Toronto, Canada; ${ }^{2}$ Johns Hopkins University, Batimore; ${ }^{3}$ Eli Lilly and Company, Indianapolis, USA; ${ }^{4}$ LBRC, LTHT, and LIRMM, University of Leeds, Leeds, UK

Background: Psoriatic arthritis (PsA) is a chronic inflammatory disease with heterogeneous musculoskeletal manifestations including enthesitis and dactylitis. Ixekizumab (IXE), an interleukin-17A antagonist, is approved in the USA for the treatment of PsA including patients with pre-existing enthesitis or dactylitis.

Objectives: To investigate the impact of IXE treatment on the resolution of enthesitis or dactylitis and whether such improvements were associated with improved function and health-related quality of life (HRQoL).

Methods: Patients with active PSA who were biologic-naïve (SPIRIT-P1; NCT01695239) or with prior inadequate response to tumour necrosis factor inhibitor(s) (SPIRIT-P2; NCT02349295) were randomised to placebo (PBO) or $80 \mathrm{mg}$ IXE every 4 weeks (IXEQ4W) or 2 weeks (IXEQ2W), after a 160 mg starting dose. All patients who were inadequate responders at Week 16 received rescue therapy (changes in background therapy). Leeds Enthesitis Index (LEI), Leeds Dactylitis Index-Basic (LDI-B), Health Assessment Questionnaire Disability Index (HAQDI), and EuroQoL-5D Visual Analogue Scale (EQ-5D VAS) were measured at Week 24. Missing data or data from inadequate responders were considered nonresponse or imputed with last observation carried forward for categorical and continuous measures, respectively. Statistical comparisons between PBO and IXE treatment groups were performed with a logistic regression model using Wald's test with treatment and study as factors. In post hoc-analyses, associations between enthesitis and dactylitis with HAQ-DI and EQ-5D VAS are based on an ANCOVA model adjusting for study and Disease Activity of Psoriatic Arthritis (DAPSA).

Results: In the integrated SPIRIT-P1 and -P2 dataset $(n=679), 403$ patients ( $59 \%$ of total) had baseline enthesitis ( $\mathrm{LEI}>0$ ) with a mean $2.9 \mathrm{LEI}$ score, and 155 patients $(23 \%$ of total) had baseline dactylitis (LDI-B $>0$ ) with a mean 56.4 LDI-B score. Relative to PBO, IXE treatment resulted in significantly higher resolution of enthesitis (SPIRIT-P1) and dactylitis (SPIRIT-P1 and -P2) after 24 weeks. ${ }^{1,2}$ In the integrated SPIRIT-P1 and -P2 dataset, both IXEQ4W and IXEQ2W had significantly higher enthesitis and dactylitis resolution than PBO treatment at Week 24 (Table). In ad-hoc analysis, IXE treatment had significantly higher resolution of enthesitis compared to PBO at the entheseal points comprising the LEI score (Table). For all PBO- and IXE-treated patients at Week 24, least squares mean (SE) HAQ-DI changes from baseline were $-0.44(0.05)$ and $-0.25(0.03 ; p<0.01)$ for patients who did and did not resolve enthesitis, and $-0.41(0.06)$ and -0.31 $(0.07 ; p=0.34)$ for patients who did and did not resolve dactylitis. Corresponding EQ-5D VAS improvements were 12.3 (2.2) and $5.8(1.5 ; \mathrm{p}=0.02)$ for patients who did and did not resolve enthesitis, and 10.8 (2.8) and $9.8(3.5 ; p=0.83)$ for patients who did and did not resolve dactylitis.
Abstract SAT0321 - Table 1. Enthesitis and Dactylitis Resolution from the Integrated SPIRIT-P1 and SPIRIT-P2 Dataset (Week 24)

\begin{tabular}{|l|c|c|c|}
\hline & PBO & IXEQ4W & IXEQ2W \\
\hline LEEl=0 & $26 / 126(21 \%)$ & $53 / 136(39 \%)^{*}$ & $49 / 141(35 \%)^{*}$ \\
\hline Lateral epicondyle $=0$ & $24 / 79(30 \%)$ & $39 / 85(46 \%)^{*}$ & $39 / 86(45 \%)$ \\
\hline Medial femoral condyle $=0$ & $23 / 79(29 \%)$ & $41 / 92(45 \%)^{*}$ & $45 / 100(45 \%)^{*}$ \\
\hline Achiles tendon insertion=0 & $19 / 64(30 \%)$ & $37 / 75(49 \%)^{*}$ & $38 / 74(51 \%)^{*}$ \\
\hline LDI-B=0 & $10 / 42(24 \%)$ & $52 / 67(78 \%)^{* *}$ & $30 / 46(65 \%)^{* *}$ \\
\hline
\end{tabular}

Conclusions: Treatment with IXE resulted in significant improvement in enthesitis and dactylitis in patients with pre-existing enthesitis or dactylitis. Resolution of enthesitis symptoms was associated with improvements in patients' function and HRQoL.

\section{REFERENCES:}

[1] Mease, et al. ARD 2017;76(1):79.

[2] Nash, et al. Lancet 2017;389(10085):2317.

Disclosure of Interest: D. Gladman Grant/research support from: Abbvie, Amgen, Celgene, Janssen, Novartis, Pfizer, UCB, Consultant for: Abbvie, Amgen, BMS, Celgene, Eli Lilly and Company, Janssen, Novartis, Pfizer, UCB, A.-M Orbai Grant/research support from: Abbvie, Celgene, Eli Lilly, Horizon, Janssen, Novartis, Pfizer, Consultant for: Eli Lilly, Janssen, Novartis, Pfizer, UCB, G. Gallo Shareholder of: Eli Lilly and Company, Employee of: Eli Lilly and Company, J. Birt Shareholder of: Eli Lilly and Company, Employee of: Eli Lilly and Company, S. Rathmann Shareholder of: Eli Lilly and Company, Employee of: Eli Lilly and Company, H. Marzo-Ortega Grant/research support from: Janssen, Speakers bureau: Abbvie, Celgene, Janssen, MSD, Novartis, Pfizer and UCB DOI: 10.1136/annrheumdis-2018-eular.2325

\section{SAT0322 THE EFFECT OF GUSELKUMAB ON DACTYLITIS: RESULTS FROM A PHASE 2 STUDY IN PATIENTS WITH ACTIVE PSORIATIC ARTHRITIS}

D. Gladman ${ }^{1}$, W.-H. Boehncke ${ }^{2}$, A.B. Gottlieb ${ }^{3}$, P. Helliwell ${ }^{4}$, P. Nash ${ }^{5}$, X.L. Xu' ${ }^{6}$, S. Xu ${ }^{6}$, Y. Wang ${ }^{6}$, E.C. Hsia ${ }^{7}$, C.S. Karyekar ${ }^{8}$, A. Deodhar ${ }^{9}{ }^{1}{ }^{1}$ Krembil Research Institute, Toronto, Canada; ${ }^{2} U$ of Geneva, Geneva, Switzerland; ${ }^{3} N Y$ Medical College, Metropolitan Hospital, New York, USA; ${ }^{4}$ U of Leeds, Leeds, UK; ${ }^{5}$ U of Queensland, Brisbane, Australia; ' Janssen Research and Development, LLC, Spring House; ' Janssen Research and Development, LLC/U Penn, Spring House/ Phila; ${ }^{8}$ Janssen Research and Development, LLC, Horsham; ${ }^{9}$ Oregon Health and Science U, Portland, USA

Background: In a Phase 2 study, Guselkumab (GUS) was shown to be safe and effective in patients (pts) w/active psoriatic arthritis (PsA).

Objectives: To evaluate the effect of GUS on dactylitis in a subset of pts w/dactylitis at baseline (BL) in the phase 2 PsA study of GUS.

Methods: Pts w/active PsA and $\geq 3 \%$ body surface area of plaque psoriasis, despite current or previous treatment, were randomised $2: 1$ to receive $100 \mathrm{mg}$ subcutaneous GUS at wks 0, 4 then every 8 weeks (wks, q8w) or placebo (PBO) during a $24 w k$ double-blind treatment period. At wk 16 , pts $w /<5 \%$ improvement in swollen and tender joint counts early escaped (EE). At wk24, the PBO group crossed over to receive GUS (wks 24, 28 then $q 8 w$ ) (PBO $\rightarrow$ GUS) and the GUS group continued receiving GUS (GUS $\rightarrow$ GUS)) through wk44. Dactylitis was assessed by scoring each digit from $0-3 \quad(0=$ absent, $1=$ mild, $2=$ moderate, $3=$ severe), for a combined score of $0-60$. Sensitivity analysis of change from BL through wk24 in dactylitic digits was performed (combined score 20). Dactylitis scores during the 24-wk double-blind treatment was analysed using LOCF imputation for missing data and EE. Dactylitis after wk24 was evaluated using observed data.

Results: Of 149 pts, 81 presented $w /$ dactylitis at $B L(P B O n=23$, mean[SD]=3.9 [3.01]; GUS $n=58$, mean[SD]=6.5 [6.15]) and 66 continued to the active treatment period (PBO $\rightarrow$ GUS $n=16$; GUS $\rightarrow$ GUS $n=50$ ). The dactylitis subset was similar to the overall population in $\mathrm{BL}$ characteristics except for higher median values for \# of swollen joints, \# of tender joints, and CRP. At wks 16 and 24, the GUS group had a significantly greater reduction in the dactylitis score (wk24 mean [SD] change from BL, PBO: -0.4 [6.06]; GUS: -3.8 [4.93]; $p=0.006$ ) and a greater $\%$ of pts $w /$ dactylitis resolution, compared to the $\mathrm{PBO}$ group (figure 1). Consistent results were obtained w/the \# digits w/dactylitis (wk24 mean [SD] change from BL, PBO: -0.2 [3.04]; GUS: -2.1 [2.21]; $p=0.003)$. Improvement in dactylitis seen at wk24 was maintained in the GUS $\rightarrow$ GUS group (wk56: mean[SD] change from $\mathrm{BL}=-5.5$ [4.84], 75\% of pts w/resolution) and the values for the $\mathrm{PBO} \rightarrow \mathrm{GUS}$ group (wk56: mean[SD] change from $B L=-4.4$ [3.50], 93.7\% of pts w/resolution) approached those of the GUS $\rightarrow$ GUS group. Improvement in dactylitis was greater in ACR20/ACR50 responders vs non-responders in GUS-treated patients (Table 